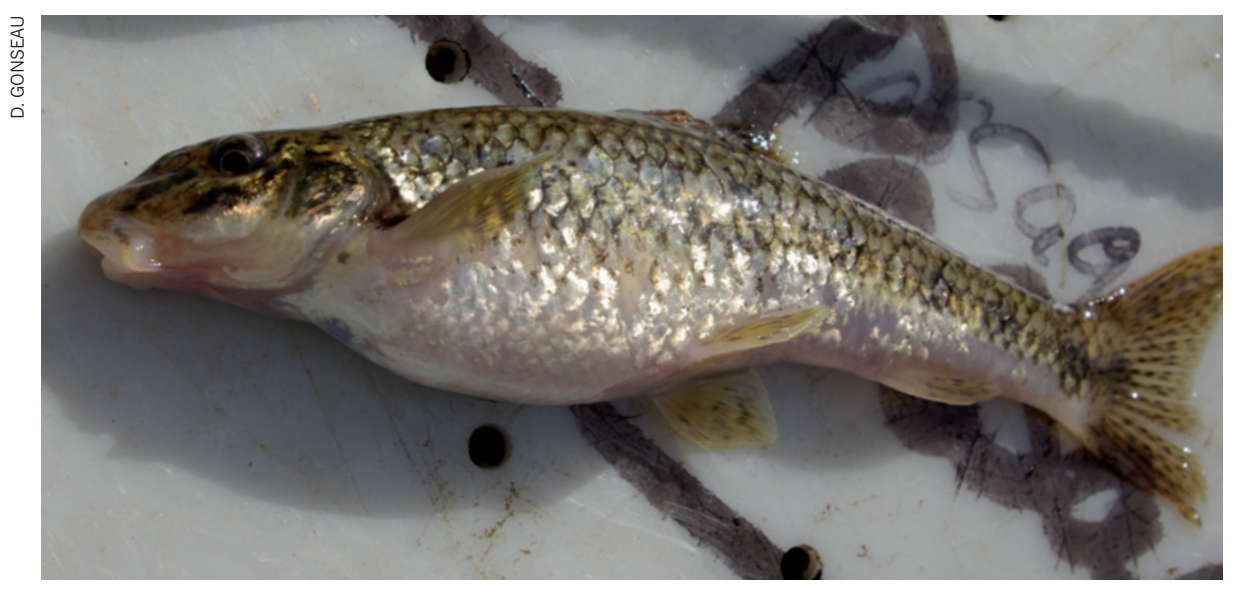

Gudgeon downstream of a wastewater-processing plant had swollen abdomens and other abnormalities. ENVIRONMENT

\title{
Drug waste harms fish
}

\section{Discharges from pharmaceutical factories contaminate rivers on three continents.}

\section{BY NATASHA GILBERT}

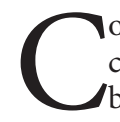

onsumers who flush unwanted contraceptives down the drain have long been blamed for giving fish more than their fair share of sex organs. Drugs excreted by patients can also taint rivers, even after passing through wastewater-processing facilities.

But evidence is accumulating that the effluent coming from pharmaceutical factories could also be carrying drugs into rivers. Many ecotoxicologists had assumed that waterquality standards, along with companies' desire to avoid wasting valuable pharmaceuticals, would minimize the extent of bioactive compounds released by factories into wastewater, and ultimately into rivers.

A string of studies suggest otherwise. In 2009, for example, researchers ${ }^{1,2}$ reported very high levels of pharmaceutical ingredients in treated effluent coming from a plant that processes wastewater from factories near Hyderabad, India. The following year, a similar discovery was made at two wastewater-treatment plants *. in New York, both of which received discharges 崖 from drug-production plants ${ }^{3}$.

Now, researchers have provided the first evidence of similar problems in Europe ${ }^{4}$, and have linked it to sex disruption in wild fish populations found in the Dore River in France. "People thought this could not happen in a country that has high environmental standards and good manufacturing practices," says Patrick Phillips, head of the National Water-Quality Assessment Program at the US Geological Survey in Troy, New York, and lead author of the US study. "The evidence from the United States and now from France shows that this is not the case."
The discovery has prompted calls for more effective oversight of the industry. The United States, the European Union, the United Kingdom and France do not have regulations limiting the concentrations of pharmaceuticals released into the aquatic environment in either municipal wastewater or in effluent from manufacturing facilities. "People think drug release is regulated, but its not," says Joakim Larsson, a pharmacologist at the University of Gothenburg in Sweden, and an author of one of the Indian studies ${ }^{2}$.

The French study investigated the health of wild gudgeon (Gobio gobio) populations in a river near a facility close to Vertolaye, owned by pharmaceutical multinational Sanofi, which produces steroid compounds. It was commissioned by the French environment ministry after anglers spotted abnormal fish in the area.

Downstream from the factory, the researchers found that on average $60 \%$, and in one case $80 \%$, of the fish had both male and female sexual characteristics. Upstream of the

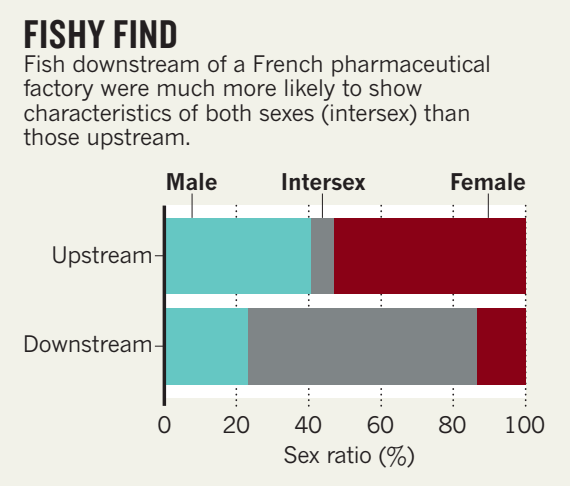

effluent discharge, such intersex fish made up just $5 \%$ of the populations (see 'Fishy find').

Male fish living downstream from the factory also had significantly higher blood levels of vitellogenin, a protein normally found in eggs, than those living upstream.

"This is a real problem," says Wilfried Sanchez, an ecotoxicologist at the French National Institute for Industrial Environment and Risks, and lead author of the study. Sexual abnormalities in gudgeon may not only prevent the fish from breeding, but also signal problems in other species, and a reduction in the fish population could have broader consequences for the river ecosystem.

\section{MAIN CULPRITS}

In results they have yet to publish, Sanchez and his colleagues identified the main pharmaceutical pollutants in the river as being dexamethasone (an anti-inflammatory and immunosuppressant), spironolactone (a diuretic that also blocks the effects of male sex hormones) and canrenone, also a diuretic. All were measured at concentrations of around 10 micrograms per litre, which is "very high" for biologically active substances, says Sanchez. It is unclear how these compounds ended up in the river

Ian Weatherhead, Sanofi's communications director, points out that because "no effect has been observed in other fish species", it is difficult to be sure how widespread the problem is. He says that the company is cooperating with regulatory agencies, researchers and ecological associations to help identify the cause of the "disturbances", which are "probably multifactorial".

Some scientists and policy-makers say that broader regulations are needed. The European Commission is now considering whether to set limits on the handful of drugs commonly found in waterways, including the anti-inflammatory drug ibuprofen and the contraceptive compound ethinylestradiol. It expects to publish its decision in the autumn as part of proposed reforms to the Water Framework Directive, which governs water pollution. The reform may, for example, demand more extensive cleaning processes in wastewater-treatment plants.

Complicating the regulators' efforts, scientists have not determined safe limits for many pharmaceuticals in the aquatic environment, or how widespread the problem is, says Susan Jobling, an aquatic ecotoxicologist at Brunel University in London. "We don't know the extent to which it is happening," agrees Larsson. "Very few manufacturing sites have been measured." -

1. Gunnarsson, L. et al. Environ. Toxicol. Chem. 28, 2639-2647 (2009).

2. Carlsson, G., Örn, S. \& Larsson, D. G. Environ. Toxicol. Chem. 28, 2656-2662 (2009).

3. Phillips, P. J. et al. Environ. Sci. Technol. 44, 4910-4916 (2010)

4. Sanchez, W. et al. Environ. Int. 37, 1342-1348 (2011). 